\title{
HERMENÊUTICA E SUPERINTERPRETAÇÃO: ADI 6341 E A QUERELA DAS COMPETÊNCIAS FEDERATIVAS
}

\author{
HERMENEUTICS AND OVERINTERPRETATION: \\ ADI 6341 AND THE QUESTION OF FEDERATIVE COMPETENCES
}

\author{
HERMENÉUTICA Y SOBREINTERPRETACIÓN: \\ ADI 6341 Y LA CUESTIÓN DE LAS COMPETENCIAS FEDERATIVAS
}

\begin{abstract}
Rafael TOMAZ DE OLIVEIRA
https://orcid.org/0000-0001-7270-4718 / http://lattes.cnpq.br/8793661579762486 / rafael_81oliveira@icloud.com Doutor em Direito Público (UNISINOS). Professor do Programa de Pós-Graduação em Direito da UNAERP, onde também lidera o Grupo de Pesquisa Justiça Política e Cidadania (DGP/CNPq). Professor da Faculdade de Direito de Ribeirão Preto da Universidade de São Paulo.

ANDRÉ KARAM TRINDADE

http://orcid.org/0000-0002-1582-1237 / http:/ / lattes.cnpq.br/002045519018718 / andrekaramtrindade@gmail.com Doutor em Teoria e Filosofia do Direito (Università Degli Studi Roma Tre/Itália). Coordenador do Programa de PósGraduação em Direito da UNIFG. Coordenador do SerTão - Núcleo Baiano de Direito e Literatura (DGP/CNPq). Membro Fundador e ex-Presidente da Rede Brasileira Direito e Literatura (RDL)

\section{RESUMO}

O presente artigo discute o fenômeno da superinterpretação no campo do Direito. Com base nos pressupostos teóricos e metodológicos da hermenêutica, o texto problematiza os limites da interpretação das normas jurídicas, a partir das Tanner's Lectures realizadas por Umberto Eco, em 1990, na Universidade de Cambridge. Em seguida, propõe um estudo de caso, ao analisar a ADI $n^{\circ}$ 6341, julgada pelo Supremo Tribunal Federal, cujo objeto envolve as competências federativas para o manejo dos mecanismos de isolamento social previstos pela Lei 13.979/2020 no contexto do enfrentamento do COVID-19. Ao final, à guisa de conclusão, sustenta que o problema do caso examinado reside na fundamentação e na aplicação equivocadas dos conceitos constitucionais, o que levou a uma segunda onda interpretativa por parte dos destinatários da decisão do Tribunal.
\end{abstract}

Palavras-chave: limites da interpretação, normas jurídicas, Umberto Eco.

\section{ABSTRACT}

This paper discusses the phenomenon of overinterpretation in the Law. Based on the theoretical and methodological assumptions of hermeneutics, the text questions the limits of the interpretation of legal norms, based on the Tanner's Lectures by Umberto Eco, in 1990, at the University of Cambridge. Then, it proposes a case study, when analyzing ADI $\mathrm{n}^{\circ} 6341$, judged by the Supreme Court of Brazil, whose object involves the federal competences for the handling of the mechanisms of social isolation provided for by Law 13.979/2020 in the context of coping with COVID-19. In the end, by way of conclusion, it points that the problem with the case examined lies in the wrong application of constitutional concepts, which led to a second wave of interpretation by the addressees of the Court's decision.

Keywords: limits of interpretation, legal norms, Umberto Eco. 


\section{RESUMEN}

Este artículo analiza el fenómeno de la sobreinterpretación en el ámbito del Derecho. A partir de los presupuestos teóricos y metodológicos de la hermenéutica, el texto problematiza los límites de la interpretación de las normas jurídicas, teniendo em cuenta las Conferencias de Tanner realizadas por Umberto Eco, en 1990, en la Universidad de Cambridge. Luego, propone un estudio de caso, al examinar la ADI n 6341, juzgada por el Tribunal Supremo Federal, cuyo objeto involucra las competencias federales para el manejo de los mecanismos de aislamiento social previstos por la Ley 13.979/2020 en el contexto de afrontamiento del COVID-19. Finalmente, a modo de conclusión, sostiene que el problema del caso examinado radica en la incorrecta fundamentación y aplicación de conceptos constitucionales, lo que llevó a una segunda ola de interpretación por parte de los destinatarios de la decisión de la Corte.

Palabras clave: límites de la interpretación, normas jurídicas, Umberto Eco.

\section{SUMÁRIO}

INTRODUÇAO; 1 PRESSUPOSTOS HERMENÊUTICOS; 2 A HERMENÊUTICA E OS LIMITES DA INTERPRETAÇÃO; 3 UM ESTUDO DE CASO: A ADI 6341 COMO UM EXERCÍCIO INTERPRETATIVO; A PRETEXTO DE UMA CONCLUSÃO; REFERÊNCIAS.

\section{INTRODUÇÃO}

A interpretação para o jurista não é uma opção, mas uma condição; um destino. Se há, portanto, algo que define a experiência jurídica, esse algo é a interpretação. Lenio Streck diz que somos condenados a interpretar; Michael Stolleis escreve que a interpretação é um problema fundamental dentro da condição humana e que sua expressão jurídica rende batalhas que a engenharia e a teoria constitucional precisam constantemente enfrentar. A modernidade produziu modificações surpreendentes nos processos de comunicação e aumentou de forma avassaladora o nível de textificação do direito. As mais diversas instituições sociais emitem textos de normas (Müller) diariamente e, no entanto, a interpretação continua sendo um problema.

Mas, afinal, qual a importância que o texto tem para a interpretação jurídica? A resposta parece simples, obvia até, porém, não é. Por mais que essa pergunta seja (re)colocada, a resposta permanece em aberto, sempre a reivindicar uma retomada e uma reconstrução de sentidos.

As decisões do Supremo Tribunal Federal são um bom laboratório para explorar essa questão. De fato, em um número frequente de casos, os votos dos ministros desafiam o texto da Constituição e tentam justificar, com malabarismos interpretativos, uma interpretação que não encontra escolio algum neste referido texto.

Um exemplo significativo dessa afirmação pode ser retirado do MS 32.033. Nesse caso, foi reafirmada pelo tribunal a possibilidade de utilização do writ, com limitação de legitimidade 
ISSN 1981-3694

(DOI): $10.5902 / 1981369462011$

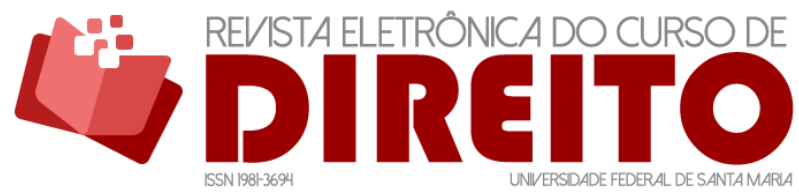

HERMENÊUTICA E SUPERINTERPRETAÇÃO: ADI 6341 E A QUERELA DAS COMPETÊNCIAS FEDERATIVAS

RAFAEL TOMAZ DE OLIVEIRA ANDRÉ KARAM TRINDADE

ativa para admitir apenas a interposição por parlamentares, para efetuar controle jurisdicional preventivo de constitucionalidade contra projetos de emenda à Constituição ou projetos de lei que se apresentem em contrariedade com a Constituição. Nesse caso, vale lembrar, que a fonte de uma tal competência é a própria jurisprudência do Supremo Tribunal. Como é cediço, não existe - no texto da Constituição de 1988 - qualquer menção a um controle jurisdicional preventivo de constitucionalidade. Pelo contrário, o texto do artigo 97, assim como o do artigo 102, I, $a$, referem-se expressamente à possibilidade de declaração de inconstitucionalidade ou interposição de Ação Direita de Inconstitucionalidade contra leis ou atos normativos. Como é possível, então, justificar uma interpretação que permita ao judiciário intervir em uma situação na qual o ato ainda não se aperfeiçoou, não possui, portanto, existência em sentido jurídico?

Mas a coisa não fica por aí. Há mais. Pode-se mencionar, ainda, a Reclamação 4.335 julgada pela corte no primeiro quadrante de 2014 - no interior da qual o tribunal assentou, por maioria de votos, o entendimento de que a eficácia das decisões que a corte profere no exercício do controle difuso de constitucionalidade, passaram a serem dotadas de eficácia erga omnes. Isso em virtude de uma série de alterações legislativas que ampliaram a dimensão vinculativa e transcendente dos efeitos das decisões, não apenas do STF, mas, também, dos Tribunais Superiores (v.g. o caso das "súmulas impeditivas de recursos", art. 38 da lei 8.038/1990; o art. 557, parágrafo $1^{\circ}$-A do Código de Processo Civil de 1973, entre outros). Assim, seria dispensável o pronunciamento do Senado (nos termos da competência fixada pela Constituição no art. 52, X) para que a decisão do Tribunal, no âmbito do controle difuso, pudesse atingir outros casos, que não aquele julgado pelo STF.

Há, por fim, o caso recentíssimo das $A D C s 43$ e 44, que discutem uma interpretação firmada pelo tribunal que não possuía nenhum tipo de aderência ao texto da Constituição e o colocava em uma situação de verdadeiro poder constituinte permanente ${ }^{1}$.

As presentes reflexões pretendem se valer do conceito de superinterpretações desenvolvido por Umberto Eco para analisar mais um caso no qual o STF foi chamado a interpretar a Constituição em uma questão polêmica e o resultado foi um conjunto de variáveis que se distanciavam, ora das premissas básicas do debate, ora do próprio texto constitucional.

Intenta-se, na verdade, realizar uma hermenêutica dessas superinterpretações. E o caso do julgamento da ADI 6341 é um excelente laboratório para esse experimento. Nele, há camadas

\footnotetext{
1 Ver, para tanto, TRINDADE, André Karam. O problema da superinterpretação no Direito brasileiro. Revista de Estudos Constitucionais, Hermenêutica e Teoria do Direito, v. 11, n. 3, p. 447-460, 2019. Disponível em: http://www.revistas.unisinos.br/index.php/RECHTD/article/view/rechtd.2019.113.10 . Acesso em: 20 mar. 2021.
} 
ISSN 1981-3694

(DOI): $10.5902 / 1981369462011$

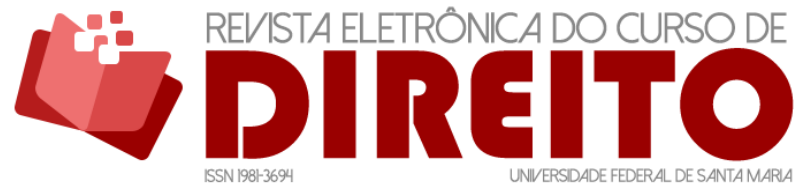

HERMENÊUTICA E SUPERINTERPRETAÇÃO: ADI 6341 E A QUERELA DAS COMPETÊNCIAS FEDERATIVAS

RAFAEL TOMAZ DE OLIVEIRA ANDRÉ KARAM TRINDADE

distintas de superinterpretação: primeiro o ministro relator não demonstra grande preocupação em articular uma interpretação adequada do próprio pedido formulado na inicial; depois, no deferimento da liminar, articula conceitos constitucionais relacionados à estruturação das competências federativas de uma forma aleatória; por fim, o espaço público ventila informações sobre o próprio conteúdo da decisão de forma distorcida, abrindo espaço para a afirmação da peça de propaganda preferida do atual presidente da república, que é dizer que o Supremo o impediu de administrar a crise sanitária gerada pela pandemia da COVID-19.

A análise começa com a indicação de alguns pressupostos hermenêuticos para que possamos assentar a objetividade da interpretação. Posteriormente, busca-se aproximar essa discussão hermenêutica da proposta de Umberto Eco de "direitos do texto", no caso da interpretação literária. Na parte final, investiga-se a ADI 6341 em seus elementos interpretativos, com ênfase para o modelo de federalismo encampado pelo texto da Constituição de 1988 e o modo como a discussão foi encaminhada no julgamento da referida ação (especialmente no que tange ao voto do relator). Ao final, tecem-se algumas considerações sobre a repercussão dessa decisão destacando como que, ao final, também ela foi superinterpretada.

\section{PRESSUPOSTOS HERMENÊUTICOS}

Há um texto escrito por Gadamer em 1959 e que antecipa, em linhas gerais, a estrutura e o movimento epistemológico da hermenêutica filosófica que aparecerá depois, de forma mais detalhada e bem-acabada, em Verdade e Método. Esse texto, intitulado Sobre o Círculo da Compreensão, ocupa-se de descrever o círculo hermenêutico, tanto em uma perspectiva da história da hermenêutica quanto com relação às particularidades específicas que Gadamer passa a nele identificar a partir de um conjunto articulado de posições filosóficas que se manifesta pela tríade Hegel - Husserl - Heidegger.

A fenomenologia, certamente, apresenta-se aqui como dimensão paradigmática. Todavia, isso se dá mais como método da investigação (Heidegger) do que propriamente como filosofia (Husserl). E é de Heidegger, de fato, que provêm o impulso mais forte para a visão apresentada por Gadamer com relação ao movimento circular da compreensão. Esse impulso, entretanto, não deriva apenas daquilo que Gadamer chama de "descoberta heideggeriana" da estrutura prévia da compreensão, mas, também, do próprio sentido que Heidegger imprime à 
ISSN 1981-3694

(DOI): $10.5902 / 1981369462011$

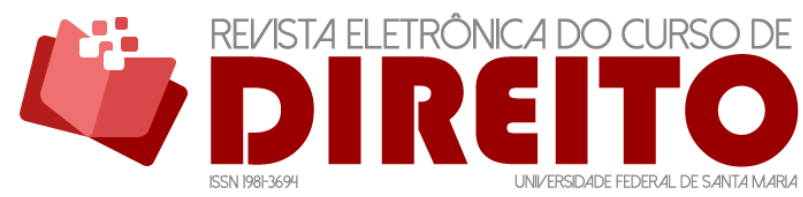

HERMENÊUTICA E SUPERINTERPRETAÇÃO: ADI 6341 E A QUERELA DAS COMPETÊNCIAS FEDERATIVAS

RAFAEL TOMAZ DE OLIVEIRA ANDRÉ KARAM TRINDADE

hermenêutica. $^{2}$

Com efeito, em Ontologia - Hermenêutica da Faticidade, Heidegger busca recuperar um sentido para a hermenêutica que, para ele, havia ficado encoberto a partir da construção levada à efeito pelo romantismo, especialmente com Schleiermacher, e, posteriormente, reforçado no historicismo, com Dilthey. Ao contrário de Schleiermacher - e, por derivação, também Dilthey Heidegger desloca o significado essencial da hermenêutica de uma Kunstlehre (predominantemente formal) para uma dimensão mais diretamente ligada ao mundo prático; ao ato de falar; de se comunicar. Realizando uma espécie de história do conceito, de modo a enfatizar as suas transformações no contexto da história da filosofia, Heidegger afirma que a origem da hermenêutica está relacionada diretamente com a fala e a comunicação e, nessa significação mais originária, estaria ela relacionada intimamente com a própria interpretação, ou seja, com a descrição da própria atividade, e não como uma observação de segundo nível a se apresentar como uma "doutrina", expressando, nessa medida, o sentido de tornar acessível ou fazer com que se manifeste isto ou aquilo sobre o que se fala.

A palavra grega hermeneuen, da qual provém etimologicamente hermenêutica, teria um significado mais propriamente ligado à anunciação de algo, interpretando um pensamento (citando Aristóteles, Heidegger afirma: “a linguagem do discurso é a interpretação através do pensamento"). ${ }^{3}$ Portanto, nesse campo de significações, hermenêutica implicaria a própria interpretação e não a doutrina da arte [Kunstlehre] da interpretação. Seu sentido mais essencial radica-se, assim, na participação de um sentido comum e que possibilita trazer as coisas à presença por meio da linguagem; mostrar uns aos outros as experiências compartilhadas.

Esse sentido manter-se-ia parcialmente preservado em Santo Agostinho, mas já indicaria, nesse contexto, algumas transformações interessantes. A primeira, certamente, diz respeito ao fato de se articular a interpretação e seus desdobramentos às Escrituras, problematizando o acesso à "vontade de Deus". A segunda, diz respeito ao fato de já aqui estar esboçado um conjunto de certos pressupostos que o intérprete deveria cuidar de cultivar virtudes interpretativas, poder-se-ia dizer - para que não deixasse de ver "sua fraqueza demonstrativa, apoiada no conteúdo da verdade." Tais pressupostos seriam: a caridade perante

\footnotetext{
${ }^{2}$ Sem embargo de pontos de partida comuns e da notória influencia de Heidegger na obra gadameriana especialmente nos procedimentos interpretativos para caracterizar a sua concepção de hermenêutica - o fato é que os projetos filosóficos dos dois filósofos apresentam diferenças importantes. Essas diferenças são exploradas por Ernildo Stein (A caminho do paradigma hermenêutico. Ijuí: Unijuí, 2017, p. 179 et seq.), para o qual remete-se o leitor.

${ }^{3}$ Cf. HEIDEGGER, Martin. Ontologie: Hermeneutik der Faktizität. Frankfurt: Vittorio Klostermann, 1988, p. 10.
} 
o texto; o conhecimento da linguagem "para que não fique suspenso diante de palavras e locuções"; o conhecimento de um conjunto de objetualidades que possam ser inseridas para ilustrar o significado, por meio de metáforas e analogias.

Abre-se, então, o caminho para a construção de uma "teoria da interpretação". Embora, e essa ressalva é feita mais de uma vez, em Agostinho - e também em Lutero - alguns elementos do significado original ainda estivessem vigentes.

Heidegger afirma que Schleiermacher, por seu turno, produziu uma restrição na ideia de hermenêutica - apagando esses elementos que ainda vindicavam nas formatações anteriores - ao retirá-la desse universo abrangente da compreensão enquanto acordo ou ajuste da dimensão de objetualidade do discurso, transformando-a exclusivamente em uma Kunstlehre. ${ }^{4}$ Dilthey, virando o problema da individualidade para a história, teria se mantido no interior dessa mesma estrutura normativa, retendo, portanto, o significado mais originário da hermenêutica.

Gadamer não só concorda com essa interpretação como vai além, buscando conformá-la com um número muito maior de pesquisa histórica e informação. Todavia, nesse caso, procurase iluminar a questão a partir da ênfase conferida por Schleiermacher aos mal-entendidos. Há outras nuances na crítica que Gadamer realiza à hermenêutica de Schleiermacher. ${ }^{5}$ Mas, para aquilo a que este ensaio se propõe, é a análise gadameriana com relação ao papel desempenhado pelos mal-entendidos que interessa mais de perto.

Como se sabe, já em Schleiermacher havia uma proposta de universalidade hermenêutica. Da mesma forma, também Schleiermacher chamava a atenção para a inevitabilidade da interpretação, expandindo essa dimensão interpretativa para outras formas de interação humana que não se materializam, necessariamente, em textos (o diálogo, as artes pictográficas, performáticas etc.). Todavia, tanto uma coisa quanto a outra, para Schleiermacher, partiam de um pressuposto básico: em todo processo comunicativo, a primeira

\footnotetext{
${ }^{4}$ Heidegger afirma que "Schleiermacher, então, reduziu a abrangente e viva ideia de Hermenêutica (como em Agostinho!) a uma " arte (doutrina da arte) da compreensão" do discurso de outras pessoas, colocando-a em relação com outras disciplinas, como a gramática e a retórica, em conexão com a dialética; essa metodologia é formal, ela envolve uma "hermenêutica geral" (Teoria e doutrina da arte da compreensão do discurso alheio em geral)" (HEIDEGGER, op. cit., p. 13).

${ }^{5}$ Gadamer reconstrói o painel da hermenêutica anterior à Schileiermacher, especialmente em Spinoza e Chladenius, apontado por ele como um percursor da hermenêutica romântica. A ideia de hermenêutica, nos dois casos, manteria - segundo Gadamer - a ênfase na compreensão e no acordo como elemento da comunicação e ponto de partida do processo interpretativo, que seria desencadeado por falhas e desajustes gerados pela falta de familiaridade com determinadas regiões temáticas. Essas hipóteses de "incompreensibilidade" encontraria em Schleiermacher uma dimensão completamente distinta, ganhando em abrangência e universalidade. "o problema para Schleiermacher não é a obscuridade da história, mas a obscuridade de um Tu ("Schleiermacher Problem ist nicht das dunklen Geschichte, sondern das des dunklen Du”). Cf.GADAMER, Hans-Georg. Wahrheit und Methode. 4 ed. Tübingen: Mohr Siebeck, 1974, p. 179.
} 
disposição, não é o entendimento mútuo. Pelo contrário, a regra é compreender mal as intenções do outro. Daí a necessidade da hermenêutica: um campo do conhecimento que poderia explorar formas que possibilitassem evitar o mal-entendido. Para Schleiermacher impulsionado pelos ventos românticos - apenas os gênios teriam a capacidade de compreender diretamente, sem a necessidade de empregar métodos ou outras estratégias formais, para interpretar corretamente o outro. Fora disso, vigeria o império do mal-entendido que, para ser desfeito, necessitaria de um treinamento e do desenvolvimento de capacidades específicas.

Gadamer, em um procedimento bem semelhante àquele já explorado por Heidegger, procura demonstrar como Schleiermacher reduziu toda a questão hermenêutica ao problema dos mal-entendidos e com isso escondeu - ou entulhou - o significado anterior, que era articulado na tradição pré-Schleiermacher. Ponto importante de se destacar é que os movimentos posteriores da hermenêutica (incluindo Dilthey) teriam mantido soterrados esse significado guiando-se pelo sentido imprimido à discussão por Schleiermacher. 0 que, de fato, ocorre, bastando lembrar, aqui, de Dilthey e a sua "doutrina do gênio". ${ }^{6}$ Mas qual seria, afinal, esse significado encoberto por Schleiermacher? $\mathrm{Na}$ interpretação gadameriana, antes de Schleiermacher a ênfase da hermenêutica estava no acordo; no common ground em meio ao qual nos movimentamos e que, no fundo, possibilita a convivência comum. Não nos mal-entendidos. Mesmo no nível do texto, o fenômeno (a evidência mais imediata que se tem) indica que tem contatos diários com eles, sobre os mais diferentes assuntos, e não ocorre nenhuma dificuldade interpretativa em sua adequada compreensão. Apenas quando esse ciclo comum é interrompido é que se faz necessário, mais uma vez, realizar aqui aquilo que Heidegger - e, nesse sentido, citado expressamente por Gadamer - chamava de “apropriação científica da compreensão”. Essa interrupção pode se dar das mais diversas maneiras, inclusive por acesso inadequado à linguagem - desconhecimento de palavras ou termos que colocam o sujeito em estado de "suspensão" perante o texto -; ou porque o texto trata de situações que reclamam uma apropriação mais rigorosa do passado para ser devidamente esclarecido; ou ainda - e, neste caso, já avançando bastante e dando uma pitada de hermenêutica filosófica para o problema -

\footnotetext{
${ }^{6}$ Nesse sentido, escreve Stein: "Os gênios, segundo Dilthey, têm a capacidade de, no universo singular da obra literária, por exemplo, apanhar sua universalidade; de, no universo singular dos fatos históricos, apanhar o elemento universal; eles produzem necessidade e verdade dos fatos humanos mediante uma aplicação da própria genialidade; os outros é que precisam de método, de lógica e de epistemologia. Ora, como a ciência é feita para os medíocres, para os menos dotados, na concepção de Dilthey, e a maioria da humanidade é medíocre e menos dotada, então temos de fornecer recursos para a humanidade, e este é o ideal da Escola Histórica. A ciência é dos medíocres, a ciência como um conjunto de procedimentos que faz com que também os medíocres cheguem à universalidade" (STEIN, Ernildo. Racionalidade e existência: o ambiente hermenêutico e as ciências humanas. 2. ed. Ijuí: Unijuí, 2008, p. 49).
} 
quando se deixam levar por um preconceito arraigado e imprimem um significado equivocado ao texto e algum interlocutor chama-lhe a atenção, entre outras tantas situações.

Em todos esses casos, o ponto de partida da experiência hermenêutica são os acertos - e não os mal-entendidos. É a disposição para se colocar de acordo com relação a algo (a "coisa mesma”) que movimenta o círculo da compreensão.

Um pequeno parêntese: alguém (jurista) poderia arguir: “mas não seria então como que represtinar o bordão in claris cessat interpretatio?” Resposta: não! Sempre há interpretação. Porém, muitas vezes, corretamente. Hoje mesmo você acordou, leu o jornal pela manhã, compreendeu boa parte das notícias e, provavelmente, interpretou corretamente os conteúdos que iam nelas veiculados. O erro do vetusto brocardo não está em indicar que, em situações de "obscuridade" (pode-se dizer: interrupções no círculo da compreensão), faz-se necessário uma mudança de comportamento com relação ao texto (ou seja: "apropriar-se cientificamente da compreensão"). Ao contrário, o erro está em pressupor que aquilo que - para o intérprete - foi “claro" não se operou como interpretação. Ora, também na "clareza” há interpretação. Porém, provavelmente, interpretação adequada. A hermenêutica filosófica coloca a todos em alerta com relação aos próprios preconceitos. Porém, não elimina a necessária constatação de que, em muitos momentos, produzem-se interpretações corretas dos diálogos que se mantem, dos textos que lidos, do mundo em que se vive. Como já afirmou Gadamer: "o interesse hermenêutico do filósofo começa justamente nos casos em que se logrou evitar o erro."7

Por outro lado, também não seria possível aqui aproximar a questão da cisão que ficou comum no direito contemporâneo entre easy e hard cases. Com efeito, Lenio Streck já havia jogado luz nessa questão esclarecendo que não há casos que sejam “em si mesmos” fáceis ou difíceis. Vale dizer: não é possível separar em um catálogo prévio casos jurídicos fáceis de casos jurídicos difíceis, aduzindo que os primeiros são resolvidos por um padrão aplicativo subsuntivo e que os segundos demandariam estratégias interpretativas mais complexas. A determinação da "dificuldade" depende das possibilidades compreensivas do intérprete para acessar aquele domínio de objetos. Portanto, é a situação hermenêutica daquele que lida com o caso que irá determinar se sua conformação jurídica se encontra numa zona de familiaridade interpretativa ou se há a necessidade de refazer projetos compreensivos mais adequados para o acesso correto ao caso e aos textos. ${ }^{8}$

\footnotetext{
${ }^{7}$ GADAMER, op. cit., p. XXI.

${ }^{8}$ Como afirma Lenio Streck: "Acreditar na cisão entre casos (fáceis) simples e casos difíceis (complexos) é pensar que o Direito se insere em uma 'suficiência ôntica', enfim, que a 'completude' do mundo jurídico pode ser 'resolvida' por raciocínios causais-explicativos, em uma espécie de 'positivismo da causalidade'.
} 


\section{A HERMENÊUTICA E OS LIMITES DA INTERPRETAÇÃO}

A ênfase da hermenêutica nas interpretações corretas, e a consequente possibilidade de se assegurar que a compreensão se ajuste a domínios de objetualidades estranhos ao intérprete, é algo que pode se apresentar como uma ligação entre aquilo que a hermenêutica filosófica procura descrever como o acontecimento da compreensão e o campo temático que Umberto Eco pretende abordar em seus textos sobre os limites da interpretação. Eco chega a mencionar Gadamer em seus escritos. Porém, em determinados momentos, o faz mais para destacar o caráter produtivo da interpretação (algo que, a rigor, não afasta a questão de base a respeito do acordo de comunicação e da possibilidade da correição interpretativa), do que, propriamente, para mencionar esse elemento que a hermenêutica reivindica como base da objetualidade interpretativa. Ainda assim, as duas posições apontam corretamente para o sentido da relação dos sujeitos com os textos e com o mundo. No mais, como ficará claro mais adiante, na resposta aos críticos de suas Tanner's Lectures, o próprio Eco irá invocar Gadamer para asseverar o mesmo sentido que se buscou retratar acima. Portanto, parece certa a existência de semelhanças entre ambos.

É certo, também, que a preocupação de Eco é ressaltar o movimento pendular entre texto e leitor, de modo a apontar para os limites da interpretação, mas, ao mesmo tempo, manter abertas as possibilidades interpretativas dos textos literários. Para aquele que lida com o Direito, por outro lado, não basta legitimar múltiplas interpretações garantindo um núcleo central de significação a partir de uma reivindicação da "intenção da obra", uma vez que a questão fulcral da legitimação interpretativa reivindica que se alcance uma resposta adequada. ${ }^{9}$ Sem embargo, em ambos os casos, pode acontecer de o intérprete simplesmente ignorar todos esses elementos e impor ao texto o sentido que mais servir ao seu desejo. Eis, então, o elemento que aproxima as duas posições (de Eco e da hermenêutica): em uma situação como

Pensar assim é esquecer que essa 'metafísica da causalidade' é apenas uma etapa necessária para chegarmos aos entes. Entretanto, não é suficiente, pois, presa à causalidade (afinal, como diz Atienza, sem discordância das demais teorias da argumentação, casos simples se resolvem dedutivamente, isto é, são os casos que demandam respostas corretas que não são discutidas), ela não atinge os entes em seu acontecer (na sua compreensão). Há, pois, um equívoco em pensar que exista uma espécie de 'institucionalização' de casos fáceis e casos difíceis, como se fosse possível colocar um divisor entre ambos. É como se existissem casos fáceis e casos difíceis em si, já de antemão demarcados. 0 problema é saber em que momento 'a suficiência ôntica', que possibilita a resolução dos casos fáceis, exige o algo a mais, isto é, em que momento essa 'falta de sentido' permite que se esteja diante de um caso difícil". (STRECK, Lenio Luiz. Verdade e consenso. 6 ed. São Paulo: Saraiva, 2017.[livro eletrônico] s. p.). ${ }^{9}$ Id., ibid., em especial o posfácio. 
essa, ambos irão afirmar, não se tratará mais de uma interpretação, mas, sim, de um ato que pode ser expressão de um voluntarismo, de uma ideologia, ou até mesmo de uma patologia.

Ademais, Eco lembra também, tal qual o faria Gadamer, que "é através de processos de interpretação que, cognitivamente, construímos mundos, atuais e possíveis”. ${ }^{10}$ Porém, apesar desse caráter constitutivo da interpretação - e de sua dimensão produtiva - essa conclusão não autorizaria afirmar que essa construção se dê de forma completamente aleatória: “Até mesmo o desconstrucionista mais radical aceita a ideia de que existem interpretações clamorosamente inaceitáveis. Isso significa que o texto interpretado impõe restrições a seus intérpretes. Os limites da interpretação coincidem com os direitos do texto". ${ }^{11}$

Lembrando Agostinho, Eco também afirma, para reforçar a ideia de "direitos do texto" que "uma interpretação, caso parecer plausível em determinado ponto do texto, só poderá ser aceita se for reconfirmada - ou pelo menos se não for questionada - em outro ponto do texto". ${ }^{12}$ E nas Tanner's lectures, quando Richard Rorty acusa sua concepção de direitos do texto de um retorno ao essencialismo (reafirmando, na visão de Rorty, distinções entre interpretar e usar textos; sentido e significado), Eco responde asseverando que o fato de nosso conhecimento ser relacional e de não podermos separar fatos de linguagem, não anula os Direitos do texto: “um texto continua sendo um parâmetro para as suas interpretações aceitáveis" ${ }^{13}$ e, portanto, “é possível estabelecer alguns limites além dos quais é possível dizer que uma determinada interpretação é ruim ou excessiva". ${ }^{14}$

$\mathrm{Na}$ conhecida polaridade que estabelece entre autor e leitor, e a estrutura pendular da interpretação que nesse âmbito se desenvolve, Eco afirma que as palavras trazidas pelo autor "são um conjunto embaraçoso de evidências materiais que o leitor não pode deixar passar em silêncio, nem em barulho". ${ }^{15}$

Mais adiante, o próprio Eco relaciona diretamente essa ideia de limites da interpretação com a hermenêutica gadameriana dizendo que, ao insistir no elemento conjetural da interpretação, Peirce teria buscado estabelecer um paradigma mínimo de aceitabilidade de uma interpretação com base num consenso da comunidade "que não é tão diferente da ideia de Gadamer de uma tradição interpretativa”. Indo além, Eco pergunta: "que tipo de garantia uma

\footnotetext{
${ }^{10}$ ECO, Umberto. Os limites da interpretação. Trad.de Pérola de Carvalho. São Paulo: Perspectiva, 2015. [livro eletrônico] s.p.

${ }^{11}$ Id., ibid., p. 23.

12 Id., ibid., p. 39.

${ }^{13}$ ECO, Umberto. Interpretação e superinterpretação. São Paulo: Martins Fontes, 2018, p. 166.

${ }^{14}$ Id., ibid., p. 167.

15 Id., ibid., p. 28.
} 
comunidade pode proporcionar?" Ao que ele mesmo responde: “Acho que ela proporciona uma garantia factual." ${ }^{16}$ Ou seja, são esses elos comuns, que nos ligam com o passado e a história cultural, que possibilitam inclusive que se avance em diversos âmbitos da experiência humana que, ao mesmo tempo, legam as coordenadas interpretativas que se deve seguir caso se queira compreender corretamente um texto. Como o próprio Eco lembra: "com as palavras podem-se fazer coisas; e não uma coisa qualquer, mas aquelas coisas que aquelas palavras estão aptas a fazer". ${ }^{17}$

\section{UM ESTUDO DE CASO: A ADI 6341 COMO UM EXERCÍCIO INTERPRETATIVO}

HAMLET - Do you see yonder cloud that's almost in shape of a camel? LORD POLONIUS - By the mass, and 'tis like a camel, indeed.

HAMLET - Methinks it is like a weasel. LORD POLONIUS - It is backed like a weasel.

HAMLET - Or like a whale? LORD POLONIUS - Very like a whale.

O trecho de Hamlet que aqui vai como epígrafe é lembrado por Umberto Eco em Os Limites da Interpretação para acentuar o que seria uma das hipóteses extremas de interpretação, que o leitor poderia assumir ao ler um texto (que, por certo, aplica-se também àquilo que se pode chamar, heideggerianamente, de mundo; ou ainda: a "natureza como texto"). Ao defender a necessidade de equilíbrio (ou um modus; uma medida para a interpretação) Eco opõe dois modelos interpretativos, retirados de duas citações. A primeira (o extremo da escassez), vem de Joseph Heller e possui o seguinte conteúdo: "no que te faz pensar aquele peixe? - Em outros peixes. No que te fazem pensar os outros peixes? - Em outros peixes." A segunda (o extremo do conteúdo imaginativo e voluntarista) é exatamente a passagem de Hamlet já mencionada: “Hamlet - Está vendo aquela nuvem com jeito de camelo? Polônio - Pela santa missa! parece mesmo um Camelo! Hamlet - Pois a mim parece uma doninha. Polônio - Por trás é como uma doninha. Hamlet - Ou como uma baleia? Polônio - Exatamente como uma baleia."

O caso que aqui se examina tem um particular parentesco com essa segunda modalidade interpretativa destacada por Eco. Todavia, antes de explorá-la, vale ainda ressaltar mais uma

${ }^{16}$ Id., ibid., p. 169.

${ }^{17}$ Id., Os limites da interpretação, op., cit., p. 58. 
ISSN 1981-3694

(DOI): $10.5902 / 1981369462011$

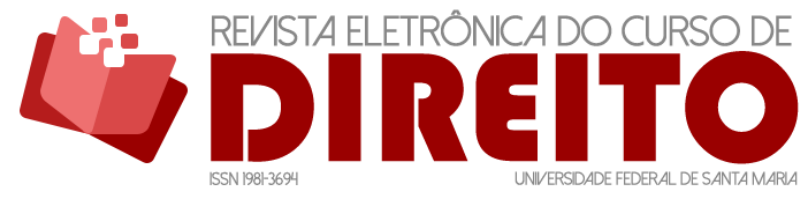

HERMENÊUTICA E SUPERINTERPRETAÇÃO: ADI 6341 E A QUERELA DAS COMPETÊNCIAS FEDERATIVAS

RAFAEL TOMAZ DE OLIVEIRA ANDRÉ KARAM TRINDADE

advertência do mestre italiano: "notem bem, suspeito que tanto Polônio quanto Hamlet tinham razão. Mas se tinham mesmo razão só o saberemos tomando a olhar para aquela nuvem." Lê-se isso com uma verve fenomenológica, "olhar para aquela nuvem" significa aqui "às coisas elas mesmas" (zu den Sachen selbst). Como já ressaltado no início dessas reflexões, busca-se aqui mais do que ressaltar as divergências interpretativas que um discurso jurídico-constitucional tende a gerar - explorar o common ground que tanto a hermenêutica quanto a abordagem de Eco acabam por destacar. É esse elemento comum que gera a possibilidade de se encontrar em posição de acordo em várias dimensões da interação humana. E o que leva a esse "colocar-se que acordo" não é um mero ajuste de opiniões, mas, sim um ajuste com relação às "coisas mesmas", sejam elas o formato de uma nuvem, o significado de um texto, ou questões jurídicas tidas como complexas. Dos acordos elementares - sob os quais se assenta a vivência cotidiana surge a possibilidade de estruturação de situações mais complexas de objetualidade (Gegenstand). Por certo que esse exercício não produzirá uma fórmula ou um "algoritmo" capaz de reproduzir, em todos os casos, esse acontecimento. Do mesmo modo, não pode ele ser demonstrado ao modo da "prova matemática". Mas é possível explorar alguns elementos desse tipo em situações concretas, vivenciadas.

Nesse sentido, o caso julgado pelo Supremo Tribunal Federal na ADI 6341 representa um bom laboratório para uma análise dos limites da interpretação dos textos jurídicos, buscando explorar essa dimensão compartilhada e que se manifesta como a dimensão mais essencial da hermenêutica ${ }^{18}$.

Com efeito, por meio da referida ação, o Supremo foi chamado a atuar para analisar a compatibilidade de dispositivos introduzidos por meio da Medida Provisória 926 (que alterou quadros regulatórios de gestão da crise sanitária instituídos pela Lei 13.979/2020) com as prescrições constitucionais que regulam a dimensão do chamado federalismo cooperativo. Sustentava o legitimado que provocou a manifestação do Tribunal que a Medida Provisória, ao introduzir alterações na Lei 13.979/2020, teria concentrado na figura do presidente da república as competências de execução de medidas restritivas - especialmente aquelas relacionadas ao isolamento social -, uma vez que tornava prerrogativa exclusiva do presidente a definição das atividades econômicas e dos serviços considerados essenciais. Os textos colocados em confronto,

\footnotetext{
${ }^{18}$ Como se sabe, a busca pelo Poder Judiciário aumenta quando o sistema político é tensionado ao limite, sendo exatamente nesses casos que perigo do ativismo exsurge com mais intensidade. Ver, nesse sentido, TRINDADE, André Karam; OLIVEIRA, Rafael Tomaz de. 0 ativismo judicial na débâcle do sistema político: sobre uma hermenêutica da crise. Revista Eletrônica do Curso de Direito da UFSM, v. 11, n. 2, p. 751 772, 2016, Disponível em: https://periodicos.ufsm.br/revistadireito/article/view/22912. Acesso em 20 mar. 2021.
} 
portanto, seriam, especialmente, os parágrafos $8^{\circ}$ e $9^{\circ}$ do artigo $3^{\circ}$ da MP 926 e o artigo 23 , inciso II, da Constituição Federal.

Encontra-se, portanto, diante de uma questão que pressupõe uma série de conteúdos que são transmitidos por meios conceitos ligados à tradição federalista e às palavras que se articulam no texto da Constituição e no âmbito da Medida Provisória com ela confrontada. ${ }^{19}$ Há também uma dimensão de não-dito - ou seja, que não está diretamente mencionada no nível apofântico dos textos mencionados no parágrafo anterior, mas que se encontram pressupostas, no nível hermenêutico, que estrutura essa discussão - que envolve elementos tais quais: que tipo de competência que se está tratando aqui? É uma competência de criação de quadros normativos? Ou é, por outro lado, uma competência de execução da lei?

O primeiro aspecto a ser destacado, do ponto de vista propriamente apofântico, é que o caput do artigo 23 faz uso da expressão “comum” para se referir a competências que seriam atribuídas, concomitantemente, à União, Estados, Distrito Federal e Municípios. ${ }^{20} 0$ inciso II afirma que, todas as pessoas políticas devem atuar para "cuidar da saúde e assistência pública". Nesse âmbito, seria possível discutir de que modo essa ação conjunta poderia ser levada a cabo. Poder-se-ia até admitir que a presidência da república desempenhasse um papel de liderança, conduzindo as discussões e buscando apresentar planos e propostas para solução articulada da administração da crise. Todavia, uma interpretação que estaria completamente fora de qualquer discussão plausível é aquela que permitiria concluir que o presidente e o núcleo de seu governo podem decidir, sozinhos, sobre tais situações.

\footnotetext{
19 Sobre o federalismo e seus problemas contemporâneos, importante consultar: ALMEIDA, Fernanda Dias Menezes de. Federação. In: CANOTILHO, J. J. Gomes; MENDES, Gilmar F.; SARLET, Ingo W.; STRECK, Lenio L. (Coord.). Comentários à Constituição do Brasil. São Paulo: Saraiva, 2013; HALBERSTAM, Daniel. Federalism: Theory, Policy, Law. In: ROSENFELD, Michel; SAJÓ, András (Eds.). The Oxford Handbook of Comparative Constitutional Law. Oxford: Oxford University Press, 2012. [livro eletrônico] s.p.; MCCRUDDEN, Christopher. State Architecture: subsidiarity, devolution, federalism and independence. In: ELLIOT, Mark Elliot. FELDMAN, David (Eds.). The Cambridge Companion to Public Law. Cambridge: Cambridge University Press, 2015, p. 193 et seq.

${ }^{20}$ Sobre a chamada cooperação vertical (que se dá entre entes de diferentes níveis federativos), Christian Starck assevera: "Em Estados democráticos, as decisões estatais encontram-se em uma relação de derivação democrática que parte da eleição parlamentar, passando pela formação do governo e pela responsabilidade do governo pela administração e suas decisões. A finalidade da imbricação política mediante formas de cooperação apresentadas é fundar decisões estatais em dois sistemas de legitimação políticos situados lado a lado, o público-central da Federação e o do Estado-membro, atribuíveis respectivamente a eleições parlamentares. A decisão estatal tomada cooperativamente deve se basear, conforme a vontade da Constituição, em uma compensação federal de interesses. Enquanto a Constituição não previr ou permitir tal compensação federal de interesses, decisões estatais sempre se fundarão apenas em uma de ambas as linhas de legitimação" (STARCK, Christian. Princípios do Federalismo e o Brasil. In: MENDES, Gilmar Ferreira; MUDROVITSCH, Rodrigo. Assembleia Nacional Constituinte de 19871988: análise crítica. São Paulo: Saraiva, 2017. [livro eletrônico] s.p.
} 
ISSN 1981-3694

(DOI): $10.5902 / 1981369462011$

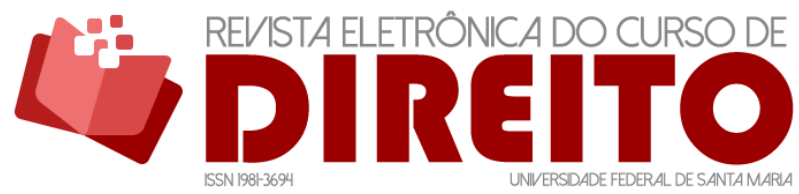

HERMENÊUTICA E SUPERINTERPRETAÇÃO: ADI 6341 E A QUERELA DAS COMPETÊNCIAS FEDERATIVAS

RAFAEL TOMAZ DE OLIVEIRA ANDRÉ KARAM TRINDADE

Um outro cenário possível, que chegou a ser articulado pela Advocacia-Geral da União (AGU), seria deslocar o parâmetro constitucional a ser analisado, afirmando que o governo, ao editar a Medida provisória 926, estaria respaldado pelo disposto no artigo 21, inciso XVIII da Constituição Federal no qual se afirma ser competência da União - de forma exclusiva "planejar e promover a defesa permanente contra as calamidades públicas, especialmente as secas e inundações”.

Importante anotar que, tanto na hipótese do artigo 21 quanto no caso do artigo 23 , se está diante de competências administrativas que se manifestam como competências de execução de leis ${ }^{21}$, e não propriamente como competências de criação de quadros normativos. As competências para criação de quadros normativos estão aglutinadas nos artigos 22 e 24 (preponderantemente) e são, como se sabe, prerrogativas dos respectivos legislativos (Congresso Nacional, no caso das competências da União; Assembleias e Câmara Distrital, no caso de Estados e Distrito Federal). O regime de edição compartilhada de textos de lei vem prescrito no artigo 24, no qual se estabelece as chamadas competências concorrentes, enquadradas dentro daquilo que, do ponto de vista doutrinário, é chamado no Brasil de "condomínio legislativo". Novamente, a prerrogativa básica de edição dessas normas é dos respectivos legislativos. No caso da União, porém, surge a possibilidade de o Presidente da República atuar, além na forma de iniciação do respectivo processo legislativo, também a partir da edição de Medidas Provisórias, nas hipóteses excepcionais previstas no artigo 62 da Constituição Federal. Todavia, é de se notar que, tanto na hipótese do artigo 21 , quanto na hipótese do artigo 23 , não se está diante de competências legislativas em sentido próprio, mas, sim, de competências administrativas, ou seja, competências de execução de leis. Não é necessário, para interpretação que aqui estamos realizando, entrar na polêmica das chamadas "competências legislativas impróprias" porque, para análise do caso, essa questão não se aplica. E, de qualquer forma, ainda que se fosse falar em competência imprópria, o seu exercício em termos de criação de quadros normativos exigiria, necessariamente, que o poder legislativo fosse acionado e processasse a questão nos termos do devido processo legislativo. Sem embargo, como já foi afirmado, essa questão não se aplica ao presente caso. O importante, aqui, é preservar uma constatação: a competência de que se trata é propriamente administrativa, de execução de lei.

Nesse sentido, ter-se-ia o seguinte framework: as competências do artigo 21 são reservadas à União que executa, com exclusão dos demais entes federativos, os quadros normativos que dispõem sobre as matérias que nele vão consignadas; já as competências do

${ }^{21}$ Sobre a competência para execução de leis, consultar STARCK, op. cit. 
artigo 23 são essencialmente comuns e devem ser exercidas em regime de cooperação. Nesse âmbito, os quadros normativos são executados por todos os entes federativos conjuntamente, em um modelo de "governança compartilhada". O Sistema Único de Saúde, inclusive, pode ser mencionado como um bom exemplo do que representa o tipo de competência da qual se fala. $E$ o mais importante: neste âmbito de competências a ação de uma unidade federativa não excluí a da outra, permitindo - talvez até sugerindo - que esta ação se dê de forma coordenada, com unidade de desígnios. Já na hipótese das competências legislativas concorrentes - como a palavra já está a sugerir - a ação concomitante dos entes federativos se dá de forma a concorrer uma com a outra, havendo aqui a necessidade de um critério normativo que determine de quem é a prerrogativa de legislar e em qual âmbito de interesses. Nesse caso, a Constituição estabelece a regra geral de preferência da União para legislar sobre assuntos de interesse geral (ou normas gerais, como aparece no artigo 24 , parágrafos $1^{\circ}$ e $4^{\circ}$ ), reservando aos Estados e ao Distrito Federal a possibilidade de emitirem leis, nas matérias ali consignadas, no seu âmbito de interesses, podendo suplementar a atividade legislativa da União na hipótese de inexistência de quadros normativos gerais sobre o conteúdo especificado (artigo 24, parágrafos $2^{\circ}$ e $3^{\circ}$ ).

Sem embargo, no caso da ADI 6341, não há que se falar em competência concorrente ${ }^{22}$, uma vez que o âmago da discussão gira em torno do problema administrativo, ou seja, de execução de leis. Inclusive porque, a rigor, a norma geral já existia e estava dada: Lei 13.979/2020. A pergunta essencial, no fundo, não era se o presidente da república poderia ou não editar Medida Provisória sobre matérias relacionadas à gestão da pandemia (embora, preliminarmente, esse fosse um dos pedidos da inicial), mas, sim, se a Medida editada pelo presidente se apresentava adequada aos comandos constitucionais no que tange aos desdobramentos das competências administrativas, de execução do quadro normativo geral posto. Por esse motivo é que se afirmou, anteriormente, que a questão das competências legislativas impróprias não se aplicava à hipótese que aqui se considera, uma vez que o problema principal não é a edição da medida provisória, mas, sim, as consequências administrativas de alguns de seus dispositivos.

\footnotetext{
${ }^{22}$ Há que se consignar que, numa perspectiva didática e especulando sobre as possíveis competências implícitas exigidas para o desdobramento das políticas públicas que seriam necessárias para levar a cabo as competências do art. 23, há quem diga, doutrinariamente, que o art. 23 também consignaria hipóteses de competência concorrente. É o caso de Fernanda Dias de Almeida, que possui um dos trabalhos mais influentes e seminais sobre o federalismo no âmbito do direito constitucional brasileiro (cf. ALMEIDA, Fernanda Dias Menezes de. Competências na Constituição de 1988. 5. ed. São Paulo: Atlas, 2010.). Sem embargo, para efeitos destas reflexões, entende-se que os conceitos de competência comum e concorrente evocam elementos distintos situando-se em patamares diferentes. As competências comuns representam um incremento em nosso modelo de federalismo cooperativo e devem ser lidas, preponderantemente, como competências administrativas.
} 
A interpretação lançada pelo Ministro Marco Aurélio, tanto na ocasião em que deferiu a liminar, quanto na ocasião de apresentação de seu voto no julgamento colegiado, extrapola os limites do "texto", exatamente porque propõe um caminho que confere ênfase à dimensão concorrente da competência quando, na verdade, não é de competência legislativa que se trata. E nem poderia sê-lo porque, na medida em que o quadro normativo já está dado, contendo hipóteses e requisitos de aplicação, a questão que se coloca é o modo que essas medidas serão executadas. Não se trata, portanto, de perguntar se o presidente poderia ou não editar MP nesse âmbito material. Trata-se de saber se, uma vez editada a medida, poderia ele concentrar em sua esfera de competências a execução das hipóteses relativas às restrições de convívio e circulação de pessoas previstas pela Lei 13.979/2020. Desse modo, em se tratando de competência administrativa, se o enquadramento que o ministro queria conferir à hipótese é aquele que contempla a ação conjunta de todos os entes, no âmbito das matérias estabelecidas no artigo 23 da Constituição Federal, ela seria, então, uma competência comum, compartilhada, mas não "concorrente". 0 ministro acerta, de algum modo, ao deferir parcialmente o pedido da ADI. Porém, em sua fundamentação, oferece uma interpretação inaceitável, desde o ponto de vista do texto (afinal, "comum" e "concorrente" são palavras que significam tipos distintos de competências federativas).

Aliás, tanto na decisão monocrática quanto no voto do ministro Marco Aurélio, existe um outro aspecto interessante de se considerar nessa perspectiva da interpretação dos textos. Algo que, inclusive, deveria ser refletido de uma forma um pouco mais ampla, questionando, afinal, qual seria o papel do legitimado que provoca o Supremo Tribunal Federal a se manifestar sobre a constitucionalidade de um ato normativo por meio de ADI. Ele representa simplesmente um "gatilho" que serve para disparar a possibilidade do julgamento sobre a matéria? Ou o Tribunal deve encará-lo como um importante ator processual com o qual ele deverá dialogar no momento de proferir o julgamento. Parece claro que a resposta adequada seguiria no segundo sentido apontado. No entanto, nas duas oportunidades, tanto na decisão quanto no voto, o ministro aparenta não demonstrar uma relação mínima de aderência com o texto da inicial. 0 primeiro ponto, já ressaltado acima, diz respeito à capitulação da modalidade de competência discutida na ação (a inicial fala o tempo todo em competência comum, e o ministro, por sua vez, a classifica como concorrente). Por outro lado, um dos pedidos sustentados pelo legitimado dizia respeito a uma eventual inconstitucionalidade formal da MP 926 por ofensa ao art. 62, parágrafo $1^{\circ}$, inciso III da Constituição Federal de 1988 (que veda edição de medidas provisórias em matérias reservadas à lei complementar). A interpretação era a seguinte: a MP 926 regulou 
ISSN 1981-3694

(DOI): $10.5902 / 1981369462011$

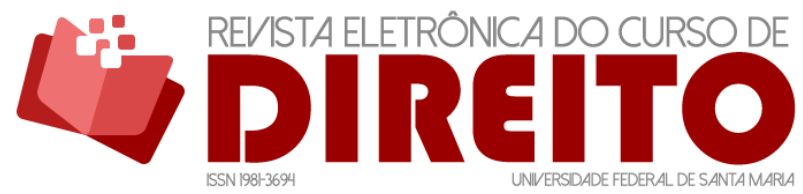

HERMENÊUTICA E SUPERINTERPRETAÇÃO: ADI 6341 E A QUERELA DAS COMPETÊNCIAS FEDERATIVAS

RAFAEL TOMAZ DE OLIVEIRA ANDRÉ KARAM TRINDADE

matérias de competência comum, no âmbito do chamado federalismo cooperativo. 0 art. 23 da Constituição, em seu parágrafo único, exige que a cooperação entre os entes federativas seja regulada por meio de lei complementar. Logo, ao editar uma Medida provisória nesse âmbito de competências, o presidente da república teria violado o art. 62 da Constituição Federal que proíbe a edição de tais atos normativos em hipóteses de reserva de lei complementar. 0 ministro respondeu refutando a interpretação formulada na inicial, dizendo que o presidente teria atuado "a tempo e modo" - diante de questão urgente e em matéria relevante - e que o conteúdo da Medida Provisória impugnava e não excluía, necessariamente, a atuação das outras unidades federativas na adoção de medidas normativas e administrativas. De se notar que a resposta do ministro não enfrenta diretamente o problema formulado pelo legitimado que acionou o Supremo Tribunal Federal. E, por outro lado, deixa em suspenso o art. 62, parágrafo $1^{\circ}$, inciso III, da Constituição Federal, uma vez que não diz claramente se a matéria é ou não reservada ao âmbito de competência da lei complementar. O fato de o presidente ter atuado "a tempo e modo" é aqui irrelevante, uma vez que, em se tratando de matéria reservada à lei complementar, mesmo estando na presença dos requisitos de fundo (relevância e urgência), o presidente estaria proibido de editar medida provisória. Em tal situação, deveria o presidente buscar os caminhos regulares de edição normativa, provocando o Congresso nos termos do art. 61 da Constituição e solicitando, conforme o caso, apreciação em regime de urgência. Mesmo o argumento de que o modo como a Medida provisória regulou a matéria não teria excluído a competência das demais unidades federativas é, de igual maneira, fora do âmbito do texto visto que, em se tratando de competência comum - de índole cooperativa - todos os entes deveriam mesmo atuar de forma concomitante. A questão é saber se aquilo que a medida provisória regulou dizia respeito ao exercício dessa cooperação em si ou não. Portanto, para afastar a interpretação de que haveria violação ao art. 62 , parágrafo $1^{\circ}$, inciso III da CF/1988, o ministro deveria ter respondido essa questão. 0 voto do ministro Marco Aurélio, dessa maneira, é um exemplo privilegiado de um exercício de superinterpretação no Direito.

De todo modo, para o caso em específico, acredita-se que a questão da reserva de lei complementar seja a contradição secundária. O ponto principal da discussão repousava na questão mais especificamente administrativa. Vale dizer: não se tratava de se perguntar se o presidente poderia ou não editar uma medida provisória para reformar a Lei 13.979/2020. A pergunta era se, assim o fazendo, poderia ele reservar apenas para si a administração das medidas restritivas que impactavam diretamente na gestão do sistema de saúde. 
ISSN 1981-3694

(DOI): $10.5902 / 1981369462011$

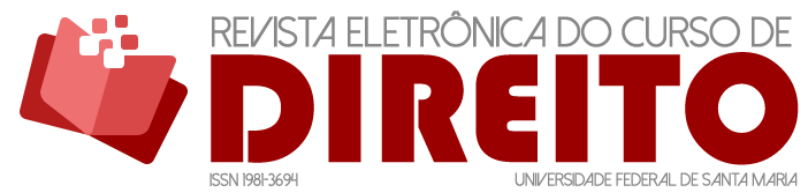

HERMENÊUTICA E SUPERINTERPRETAÇÃO: ADI 6341 E A QUERELA DAS COMPETÊNCIAS FEDERATIVAS

RAFAEL TOMAZ DE OLIVEIRA ANDRÉ KARAM TRINDADE

Não obstante, resta ainda analisar a interpretação que procura alocar a atividade do presidente (especialmente no que tange ao que vai estabelecido no art. $1^{\circ}$ da MP 926, no que se refere aos parágrafos $8^{\circ}$ e $9^{\circ}$ da Lei 13.979/2020), não na hipótese do artigo 23, II, mas, sim, naquela insculpida no artigo 21, XVIII da Constituição Federal.

A primeira objeção que pode ser apresentada à tentativa de se colocar o artigo 21, inciso XVIII da Constituição Federal como o parâmetro correto para o caso é a de que, se assim o fizessem, estar-se-ia, automaticamente, excluindo a ação dos demais entes federativos do manuseio dos instrumentos de contenção da pandemia estabelecidos pela Lei 13.979/2020. Com efeito, no artigo 21 da Constituição Federal vão discriminadas as competências administrativas exercidas, exclusivamente, pelo governo da União. Vejam-se, como exemplos, o inciso II (declarar a guerra e celebrar a paz); ou o inciso VII (emitir moeda). Obviamente, o enfrentamento de uma crise sanitária, com impactos sensíveis ao sistema de saúde, não pode ser feito de forma unilateral pelo governo da União. Menciona-se isso não porque alguma mística universal apontaria para essa direção. Pelo contrário, essa é uma constatação textual, haja visto que a Constituição (artigos 196-198) estabeleceu os marcos de uma gestão compartilhada do sistema de saúde, da qual participam todas as esferas de governo (essa afirmação é um truísmo; porém, um truísmo necessário). Logo, é impossível sustentar que a competência de execução das medidas de contenção da epidemia de COVID-19 possa ser manejada exclusivamente pelo Presidente da República.

No entanto, ainda seria possível afirmar que a hipótese não trata de um problema de gestão da saúde, mas, sim, de gestão de uma situação de calamidade pública. Essa assertiva, para quem postula esse tipo de interpretação, traria novamente a questão para o âmbito do art. 21, XVIII da Constituição Federal, retirando-a da zona de incidência do artigo 23, II. Todavia, mais uma vez, essa interpretação não encontra abrigo no “texto". Primeiro, porque essa competência diz respeito a planejamento permanente. Por outro lado, a justificativa para a existência de medidas de restrição de circulação e aglomeração de pessoas está fundada sobre a necessidade de conter o avanço da doença com o intuito de não sobrecarregar o sistema de saúde. Portanto, é certo que o manuseio desses instrumentos impactaria (como está impactando) diretamente a gestão deste mesmo sistema. Como a gestão desse sistema é de índole cooperativa e compartilhada, as decisões que levariam a utilização desses mecanismos da Lei 13.979/2020, também deveriam sê-lo. O que nos traz de volta para o arco de influências do artigo 23 e da dinâmica do federalismo cooperativo. 
ISSN 1981-3694

(DOI): $10.5902 / 1981369462011$

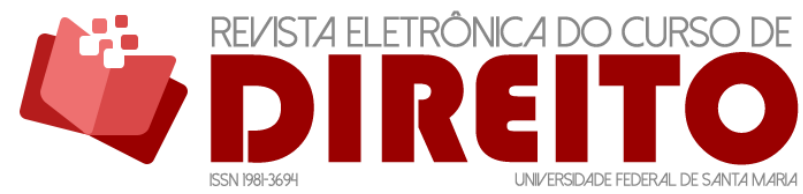

HERMENÊUTICA E SUPERINTERPRETAÇÃO: ADI 6341 E A QUERELA DAS COMPETÊNCIAS FEDERATIVAS

RAFAEL TOMAZ DE OLIVEIRA ANDRÉ KARAM TRINDADE

O pomo da discórdia, desse modo, não estaria em uma escolha binária presidente v.s. governadores, mas, sim, na imposição levada a efeito pela MP 926 de concentrar em torno do presidente as decisões executivas das medidas previstas pela Lei 13.979/2020, uma vez que se estabelecia que somente a ele caberia definir o que e quais seriam as atividades e serviços considerados essenciais.

\section{A PRETEXTO DE UMA CONCLUSÃO}

O problema das superinterpretações em direito é que elas não terminam na ação institucional do Poder Judiciário. Ao contrário, como essa mesma ação gera uma serie de consequências políticas, o espaço público de discussões também é invadido por superinterpretações, tanto da Constituição quanto da própria decisão assentada. Claro que há o risco da repercussão - principalmente aquela medida pelo termômetro dos jornais simplesmente replicar lugares comuns, sem buscar investigar as condições textuais que definem os limites do debate.

Veja-se, por exemplo, o que disse o articulista Demetrio Magnoli em sua coluna no Jornal Folha de São Paulo a respeito da decisão do Supremo na ADI 6341: "Diante da criminosa negligência de Bolsonaro, o STF produziu interpretação criativa do texto constitucional, vetando a interferência federal nas decisões sanitárias estaduais. Daí, decorreram os planos incongruentes das quarentenas e flexibilizações em curso."23 Sem embargo dos equívocos conceituais que existem no voto do ministro Marco Aurélio e sobre os quais já se discorreu neste texto, o fato é que, dentre todas as críticas que podem ser feitas à decisão do STF na ADI 6341, a mais equivocada - por que distante a quilômetros do texto - é de que ela representa o exercício de "interpretação criativa". No resultado, a decisão afirma algo que a Constituição estabelece para o desenho de competências federativas numa hipótese como essa que se está vivendo. O problema está na fundamentação e no manejo equivocado dos conceitos constitucionais, algo que acabou a levar a interpretações criativas pelos destinatários da decisão do Tribunal. Ademais, a interpretação do articulista não respeita os limites do texto na medida em que propaga a falsa informação de que a decisão da ADI 6341 teria vetado a "interferência federal nas decisões sanitárias estaduais”. Como já afirmado, a decisão não veta a participação

\footnotetext{
${ }^{23}$ MAGNOLI, Demétrio. O Vírus Governa o Brasil. Folha de São Paulo. [s.l]. 20 jul. 2020. Disponível em: https://www1.folha.uol.com.br/colunas/demetriomagnoli/2020/08/o-virus-governa-o-brasil.shtml Acesso em 20 mar. 2021.
} 
da União nos processos de tomada de decisão (o que não poderia fazer, uma vez que seria contrária à Constituição). O que ela faz é - simplesmente - afirmar que o governo da União não pode decidir sozinho sobre questões ligadas às medidas de isolamento social e que tipo de serviço ou atividade econômica poderiam continuar a funcionar nesse contexto.

Já Bruno Boghossian consegue se manter em uma situação de maior proximidade com relação ao sentido do texto. De forma correta, além de acertar na interpretação da decisão, ele também destaca a manipulação de seu conteúdo e o consequente uso propagandístico feito pelo Presidente da República: "Bolsonaro mentiu de novo ao dizer que o STF 'decidiu que as medidas restritivas eram de competência exclusiva de governadores e prefeitos'. A ideia era jogar na conta desses políticos o desemprego provocado pela paralisação da economia. Ele só não quis dizer que o tribunal apenas definiu a competência de estados e municípios, apontando que o governo federal também deveria participar desse trabalho -o que o presidente se recusou a fazer." 24 Como reparo, faltou apenas deixar um pouco mais claro que essa definição não parte de uma atitude voluntarista do tribunal, mas da interpretação que este confere ao texto da Constituição de 1988 e ao sistema por ela estabelecido nos termos de um federalismo cooperativo.

Quem também procurou esclarecer, de forma mais adequada, a interpretação da decisão da ADI 6341, foi Fausto Macedo: “Mas tudo isso não afasta a competência da União Federal em legislar em termos gerais sobre a matéria, atendidos os interesses regionais que são atinentes ao Estado membro e ao Distrito Federal como unidades federativas." 25

O governo federal, por outro lado, buscou fazer o que pôde para propagandear a falácia da exclusão decisória. Os meios de comunicação, que divulgavam os pronunciamentos oficiais, por sua vez, poucos esforços faziam para esclarecer os problemas interpretativos existentes nessas formulações. ${ }^{26}$

Outras notícias repercutiram - sem nenhum tipo de abordagem crítica - o voto do ministro Marco Aurélio e sua interpretação que indicava a competência concorrente para a

\footnotetext{
${ }^{24}$ BOGHOSSIAN, Bruno. Com 100 mil mortos, Bolsonaro quer imunidade na catástrofe do coronavírus. Folha de São Paulo. [s.l]. 8 ago. 2020. Disponível em: https://www1.folha.uol.com.br/colunas/brunoboghossian/2020/08/com-100-mil-mortos-bolsonaro-quer-imunidade-na-catastrofe-do-coronavirus.shtml . Acesso em: 20 mar. 2021.

${ }^{25}$ ROMANO, Rogério Tadeu. O município e as regras no combate à covid-19. Estadão. [s.l]. 29 jun. 2020. Disponível em: https://politica.estadao.com.br/blogs/fausto-macedo/o-municipio-e-as-regras-nocombate-a-covid-19/. Acesso em: 20 mar. 2021.

${ }^{26}$ A título de exemplo, conferir: https://g1.globo.com/rj/rio-de-janeiro/video/apoiamos-todas-elas-dizpazuello-sobre-medidas-adotadas-por-estados-e-municipios-8764613.ghtml. E também: https://www1.folha.uol.com.br/equilibrioesaude/2020/08/bolsonaro-diz-que-fez-o-possivel-e-oimpossivel-para-evitar-mortes-por-covid-19.shtml.
} 
gestão da crise. Em uma delas, lia-se o seguinte: “É importante lembrar que, de acordo com decisão do STF, a competência dos três entes federativos é concorrente e, logo, municípios também podem legislar sobre o tema. Nesse ponto identifica-se, inclusive, outra dimensão importante de análise do enfrentamento à pandemia no Brasil." 27 Como comentário adicional, fica apenas o registro da perplexidade de como uma discussão envolvendo a competência administrativa para definir atividade econômica e serviços essenciais em contextos que imponham a aplicação dos mecanismos previstos na Lei $13.979 / 2020$, se transformam em competências “para legislar”.

Em suma, na situação que envolveu o julgamento da ADI 6341 e sua repercussão futura, tem-se a sensação de repetir o diálogo de Hamlet e Polônio, lembrado por Umberto Eco, sobre o formato da nuvem que observavam. No caso, a conclusão do mestre italiano continua ressoando: para saber com alguma precisão qual a melhor interpretação para o caso, é preciso observar aquela nuvem; nesse caso, a nuvem é a Constituição e o paradoxo é que, aqueles que para ela olharam, pouco foram ouvidos nesse debate surreal da história brasileira recente.

\section{REFERÊNCIAS}

ALMEIDA, Fernanda Dias Menezes de. Competências na Constituição de 1988. 5. ed. São Paulo: Atlas, 2010.

ALMEIDA, Fernanda Dias Menezes de. Federação. In: CANOTILHO, J. J. Gomes; MENDES, Gilmar F.; SARLET, Ingo W.; STRECK, Lenio L. (Coord.). Comentários à Constituição do Brasil. São Paulo: Saraiva, 2013.

BOGHOSSIAN, Bruno. Com 100 mil mortos, Bolsonaro quer imunidade na catástrofe do coronavírus. Folha de São Paulo. [s.l]. 8 ago. 2020. Disponível em:

https: / /www1.folha.uol.com.br/colunas/bruno-boghossian/2020/08/com-100-mil-mortosbolsonaro-quer-imunidade-na-catastrofe-do-coronavirus.shtml . Acesso em: 20 mar. 2021.

BRASIL. Constituição Federal. Diário Oficial da República Federativa do Brasil, Brasília, 5 out. 1988. Disponível em: http://www.planalto.gov.br/ccivil_03/constituicao/constituicao.htm . Acesso em: 18 mar. 2021.

BRASIL. Lei 13.979, de 6 de fevereiro de 2020. Dispõe sobre as medidas para enfrentamento da emergência de saúde pública de importância internacional decorrente do coronavírus responsável pelo surto de 2019. Diário Oficial da União, Brasília, 7 fev. 2020. Disponível em:

\footnotetext{
27 SANDIM, Tatiana Lemos; LIMA-SILVA, Fernanda. Governos estaduais na berlinda: uma análise dos limites e possibilidades no enfrentamento ao Covid-19. Estadão. [s.l]. 2 jul. 2020. Disponível em: https://politica.estadao.com.br/blogs/gestao-politica-e-sociedade/governos-estaduais-na-berlinda-umaanalise-dos-limites-e-possibilidades-no-enfrentamento-ao-covid-19/ . Acesso em: 20 mar. 2021.
} 
http://www.planalto.gov.br/ccivil_03/_ato2019-2022/2020/lei/l13979.htm . Acesso em: 18 mar. 2021.

BRASIL. Lei 5.869, de 11 de janeiro de 1973. Código de Processo Civil. Diário Oficial da União, Brasília, 17 jan. 1973. Disponível em:

http://www.planalto.gov.br/ccivil_03/leis/_5869impressao.htm . Acesso em: 18 mar. 2021.

BRASIL. Medida Provisória n ${ }^{\circ}$ 926, de 20 de março de 2020. Altera a Lei $n^{\circ} 13.979$, de 6 de fevereiro de 2020, para dispor sobre procedimentos para aquisição de bens, serviços e insumos destinados ao enfrentamento da emergência de saúde pública de importância internacional decorrente do coronavírus.. Diário Oficial da União, Brasília, 20 mar. 2020. Disponível em: http://www.planalto.gov.br/ccivil_03/_ato2019-2022/2020/Mpv/mpv926.htm . Acesso em: 18 mar. 2021.

BRASIL. Supremo Tribunal Federal. Ação Direta de Inconstitucionalidade $n^{\circ}$ 6341. ADI 6341. Partido Democrático Trabalhista (PDT). Relator: Ministro Marco Aurélio. 23 mar. 2020. Disponível em: http: //portal.stf.jus.br/processos/detalhe. asp?incidente=5880765 . Acesso em: 18 mar. 2021.

ECO, Umberto. Interpretação e superinterpretação. São Paulo: Martins Fontes, 2018.

ECO, Umberto. Os limites da interpretação. Trad.o de Pérola de Carvalho. São Paulo: Perspectiva, 2015.

GADAMER, Hans-Georg. Wahrheit und Methode. 4 ed. Tübingen: Mohr Siebeck, 1974.

HALBERSTAM, Daniel. Federalism: Theory, Policy, Law. In: ROSENFELD, Michel; SAJÓ, András, (Eds.). The Oxford Handbook of Comparative Constitutional Law. Oxford: Oxford University Press, 2012.

HEIDEGGER, Martin. Ontologie: Hermeneutik der Faktizität. Frankfurt: Vittorio Klostermann, 1988.

MAGNOLI, Demétrio. O Vírus Governa o Brasil. In: Folha de São Paulo, 20.07.2020, Disponível em: https://www1.folha.uol.com.br/colunas/demetriomagnoli/2020/08/o-virus-governa-obrasil.shtml . Acesso em: 20 mar. 2021.

MCCRUDDEN, Christopher. State Architecture: subsidiarity, devolution, federalism and independence. In: ELLIOT, Mark; FELDMAN, David (Eds.). The Cambridge Companion to Public Law. Cambridge: Cambridge University Press, 2015.

ROMANO, Rogério Tadeu. O município e as regras no combate à covid-19. Estadão. [s. l]. 29 jun. 2020. Disponível em: https://politica.estadao.com.br/blogs/fausto-macedo/o-municipio-e-asregras-no-combate-a-covid-19/ . Acesso em: 20 mar. 2021.

SANDIM, Tatiana Lemos; LIMA-SILVA, Fernanda. Governos estaduais na berlinda: uma análise dos limites e possibilidades no enfrentamento ao Covid-19. Estadão. [s.l]. 2 jul. 2020. Disponível em: https: / / politica.estadao.com.br/blogs/gestao-politica-e-sociedade/governos-estaduais-naberlinda-uma-analise-dos-limites-e-possibilidades-no-enfrentamento-ao-covid-19/ . Acesso em: 20 mar. 2021. 
STARCK, Christian. Princípios do Federalismo e o Brasil. In: MENDES, Gilmar; MUDROVITSCH, Rodrigo (Org.). Assembleia Nacional Constituinte de 1987-1988: análise crítica. São Paulo: Saraiva, 2017.

STEIN, Ernildo. A caminho do paradigma hermenêutico. ljuí: Unijuí, 2017.

STEIN, Ernildo. Racionalidade e existência: o ambiente hermenêutico e as ciências humanas. 2 ed. Ijuí: Unijuí, 2008.

STRECK, Lenio Luiz. Verdade e consenso. 6 ed. São Paulo: Saraiva, 2017.

TRINDADE, André Karam. O problema da superinterpretação no Direito brasileiro. Revista de Estudos Constitucionais, Hermenêutica e Teoria do Direito, v. 11, n. 3, p. 447-460, 2019. ISSN 2175-2168. DOI: https://doi.org/10.4013/rechtd.2019.113.10 . Disponível em: http://www.revistas.unisinos.br/index.php/RECHTD/article/view/rechtd.2019.113.10 . Acesso em: 20 mar. 2021.

TRINDADE, André Karam; OLIVEIRA, Rafael Tomaz de. 0 ativismo judicial na débâcle do sistema político: sobre uma hermenêutica da crise. Revista Eletrônica do Curso de Direito da UFSM, v. 11, n. 2, p. 751-772, 2016. ISSN 1981-3694. DOI: https://doi.org/10.5902/1981369422912 . Disponível em: https://periodicos.ufsm.br/revistadireito/article/view/22912 . Acesso em 20 mar. 2021.

Recebido em: 30.10.2020 / Aprovado em: 18.11.2020 / Publicado em: 22.04.2021

\section{COMO FAZER REFERÊNCIA AO ARTIGO (ABNT):}

OLIVEIRA, Rafael Tomaz; TRINDADE, André Karam. Hermenêutica e Superinterpretação: ADI 6341 e a Querela das Competências Federativas. Revista Eletrônica do Curso de Direito da UFSM, Santa Maria, RS, v. 15, n. 3, e62011, set./dez. 2020. ISSN 1981-3694. DOI: http://dx.doi.org/10.5902/1981369462011. Disponível em: https://periodicos.ufsm.br/revistadireito/article/view/62011 Acesso em: dia mês. ano.

Direitos autorais 2020 Revista Eletrônica do Curso de Direito da UFSM

Editores responsáveis: Rafael Santos de Oliveira e Angela Araujo da Silveira Espindola

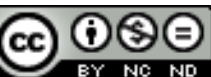

Esta obra está licenciada com uma Licença Creative Commons Atribuição-NãoComercial-SemDerivações 4.0 Internacional.

\section{SOBRE OS AUTORES}

Rafael Tomaz de Oliveira

Doutor em Direito Público pela Universidade do Vale do Rio dos Sinos (2013). Possui Mestrado em Direito pela Universidade do Vale do Rio dos Sinos (2007) e Graduação em Direito pela Faculdade de Direito de Franca (2005). Professor do Departamento de Direito Público da Faculdade de Direito de Ribeirão Preto da Universidade de São Paulo (USP) na Área de Teoria Geral do Estado e Direito Constitucional. Professor Titular do Programa de Pós-Graduação em Direito da Universidade de Ribeirão Preto (UNAERP/SP), nos cursos de Mestrado e Doutorado. Líder do Grupo de Pesquisa Justiça Política e Cidadania, vinculado à Universidade de Ribeirão Preto (SP). Tem experiência na área de Direito, com ênfase em Direito Público, atuando principalmente nos seguintes temas: Direito Constitucional e concreção de Direitos Coletivos; Ciência Política e Teoria do Estado; Filosofia do Direito e Hermenêutica Jurídica. 
ISSN 1981-3694

(DOI): $10.5902 / 1981369462011$

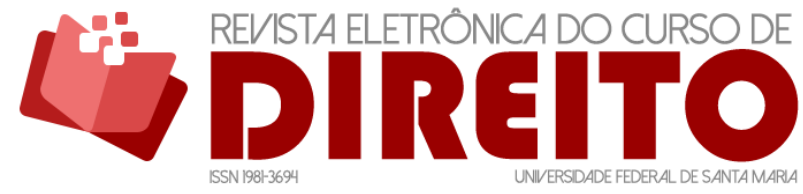

HERMENÊUTICA E SUPERINTERPRETAÇÃO: ADI 6341 E A QUERELA DAS COMPETÊNCIAS FEDERATIVAS

RAFAEL TOMAZ DE OLIVEIRA ANDRÉ KARAM TRINDADE

\section{ANDRÉ KARAM TRINDADE}

Graduação em Direito (ULBRA), Mestrado em Direito Público (UNISINOS) e Doutorado em Teoria e Filosofia do Direito (Università Degli Studi Roma Tre/Itália). Coordenador do Programa de Pós-Graduação Stricto Sensu em Direito da UniFG, onde também coordena o SerTão - Núcleo Baiano de Direito e Literatura (DGP/CNPq). Professor Externo do Programa de Doctorado em Ciencias Jurídicas y Sociales da Universidad de Málaga (Espanha). Foi presidente da Rede Brasileira Direito e Literatura (2014-2018). Editor-Chefe da ANAMORPHOSIS - Revista Internacional de Direito e Literatura. Produtor Executivo do Programa Direito \& Literatura, exibido semanalmente pela TV JUSTIÇA. Membro do Grupo de Investigación Intertextos entre el Derecho y la Literatura (USFQ/Equador). Tem experiência na área do Direito, com ênfase na Teoria do Direito, Filosofia do Direito e Direito Público, atuando principalmente nos seguintes temas: direito constitucional, hermenêutica jurídica, direito e literatura. Membro do Comitê de Área Interdisciplinar (Câmara de Ciências Sociais e Aplicadas e Humanidades) da CAPES, de 2010 a 2013. Consultor Ad Hoc da Área do Direito da CAPES, FAPERGS e FAPESB. Membro da Comissão de Estudos Constitucionais da OAB/RS. Sócio do Escritório Streck \& Trindade Advogados Associados. 